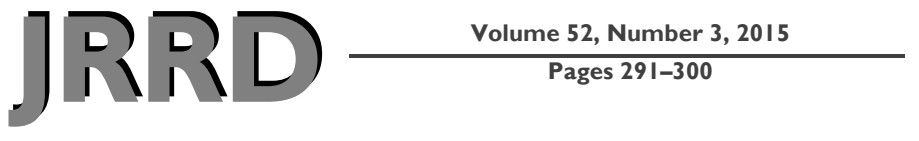

\section{Pressure ulcer risk of patient handling sling use}

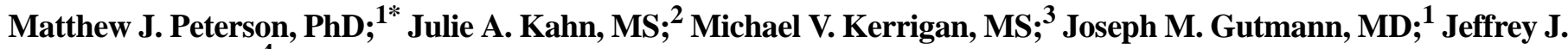 \\ Harrow, MD, $\mathbf{P h D}^{4}$ \\ ${ }^{1}$ Department of Veterans Affairs Health Services Research and Development Center of Innovation on Disability and \\ Rehabilitation Research, James A. Haley Veterans' Hospital, Tampa, FL; ${ }^{2}$ Department of Chemical and Biomedical \\ Engineering, University of South Florida, Tampa, FL; ${ }^{3}$ U.S. Patent and Trademark Office, Alexandria, VA; ${ }^{4}$ Audie L. \\ Murphy Memorial Veterans Hospital, San Antonio, TX
}

\begin{abstract}
Patient handling slings and lifts reduce the risk of musculoskeletal injuries for healthcare providers. However, no published evidence exists of their safety with respect to pressure ulceration for vulnerable populations, specifically persons with spinal cord injury, nor do any studies compare slings for pressure distribution. High-resolution interface pressure mapping was used to describe and quantify risks associated with pressure ulceration due to normal forces and identify at-risk anatomical locations. We evaluated 23 patient handling slings with 4 nondisabled adults. Sling-participant interface pressures were recorded while participants lay supine on a hospital bed and while they were suspended during typical patient transfers. Slingparticipant interface pressures were greatest while participants were suspended for all seated and supine slings and exceeded $200 \mathrm{~mm} \mathrm{Hg}$ for all seated slings. Interface pressures were greatest along the sling seams (edges), regardless of position or sling type. The anatomical areas most at risk while participants were suspended in seated slings were the posterior upper and lower thighs. For supine slings, the perisacral area, ischial tuberosities, and greater trochanters were most at risk. The duration of time spent in slings, especially while suspended, should be limited.
\end{abstract}

Key words: decubitus ulcer, interface pressure, patient handling, patient handling sling, patient lifting, patient moving and lifting, patient repositioning, pressure sore, pressure ulcer, pressure ulcer risk, spinal cord injury.

\section{INTRODUCTION}

\section{Pressure Ulcers and Spinal Cord Injury}

Pressure ulcers (PUs) are a serious, costly, and lifelong complication experienced by individuals with spinal cord injury (SCI). Approximately 273,000 persons with SCI live in the United States today, and approximately 12,000 new injuries occur each year [1]. Persons with SCI are at extreme risk for developing PUs because of lack of sensation, immobility, moisture, and multiple other risk factors [2]. The prevalence of PUs in persons with SCI ranges from 14 to 32 percent, and recurrence rates have been reported to range from 31 to 79 percent [3]. PUs account for approximately one-third of all Department of Veterans Affairs (VA) SCI admissions and over half of all hospital days for veterans with SCI [3]. The cost to manage one full-thickness PU can exceed

\footnotetext{
Abbreviations: $\mathrm{HOB}=$ head of bed, $\mathrm{PU}=$ pressure ulcer, $\mathrm{SCI}=$ spinal cord injury, SD = standard deviation, VA = Department of Veterans Affairs.

*Address all correspondence to Matthew J. Peterson, PhD; HSR\&D Center of Innovation on Disability and Rehabilitation Research (CINDRR), James A. Haley Veterans' Hospital (151R), 8900 Grand Oak Cir, Tampa, FL 33637; 813-5583979; fax: 813-558-3990. Email: Matthew.Peterson1@va.gov http://dx.doi.org/10.1682/JRRD.2014.06.0140
} 
$\$ 70,000$ [4], and in the United States, more than \$17 billion is spent on PU treatments annually [5]. The VA alone spends $\$ 100$ million annually on just primary diagnoses of PUs for veterans with SCI [6].

The National Pressure Ulcer Advisory Panel defines a $\mathrm{PU}$ as a "localized injury to the skin and/or underlying tissue usually over a bony prominence, as a result of pressure, or pressure in combination with shear and/or friction" [7]. High pressure applied to an area of skin over a length of time will inevitably cause tissue damage [8-9] in addition to tissue deformation [10]. PUs are most commonly found over and around bony prominences, locations where interface pressures are the greatest. The majority of PUs are found in the gluteal and sacral regions [11], principally at the ischial tuberosities, sacrum, and coccyx.

\section{Safe Patient Handling Equipment}

Mechanical lifting technologies have been developed to reduce musculoskeletal injuries to caregivers performing patient handling tasks (e.g., lifting, repositioning, transfers). Experts advocate using engineering solutions such as mechanical or powered patient lifts (ceiling- or floor-based) and friction-reducing devices to reduce the risk of injury associated with patient handling [12-14]. The universal sling (i.e., a full-body seated sling) is the most common lifting aid used to transfer and transport dependent patients, including between bed and wheelchair or dependency chair and vice versa, chair and commode, or bed and stretcher. Figure 1 shows an example of an individual suspended in a universal sling. Furthermore, current nursing practice is to use universal slings and lifts for all transfers and transports involving dependent patients, as taught by practice algorithms in collaboration with the National Institute for Occupational Safety and Health, the Veterans Health Administration, and the American Nurses Association [15].

This research was conducted in response to concerns regarding the possible contribution that patient handling slings may play in PU development in vulnerable populations, specifically persons with SCI. To date, no evidence has been published that links the use of slings and lifts to pressure ulceration, and no literature exists that describes the interface pressures developed during suspension from patient handling slings. However, before exposing persons with SCI to an experimental protocol of various sling types, we decided to perform the first trials on healthy nondisabled volunteers. The reason for this decision was safety—a nondisabled participant would be able to speak

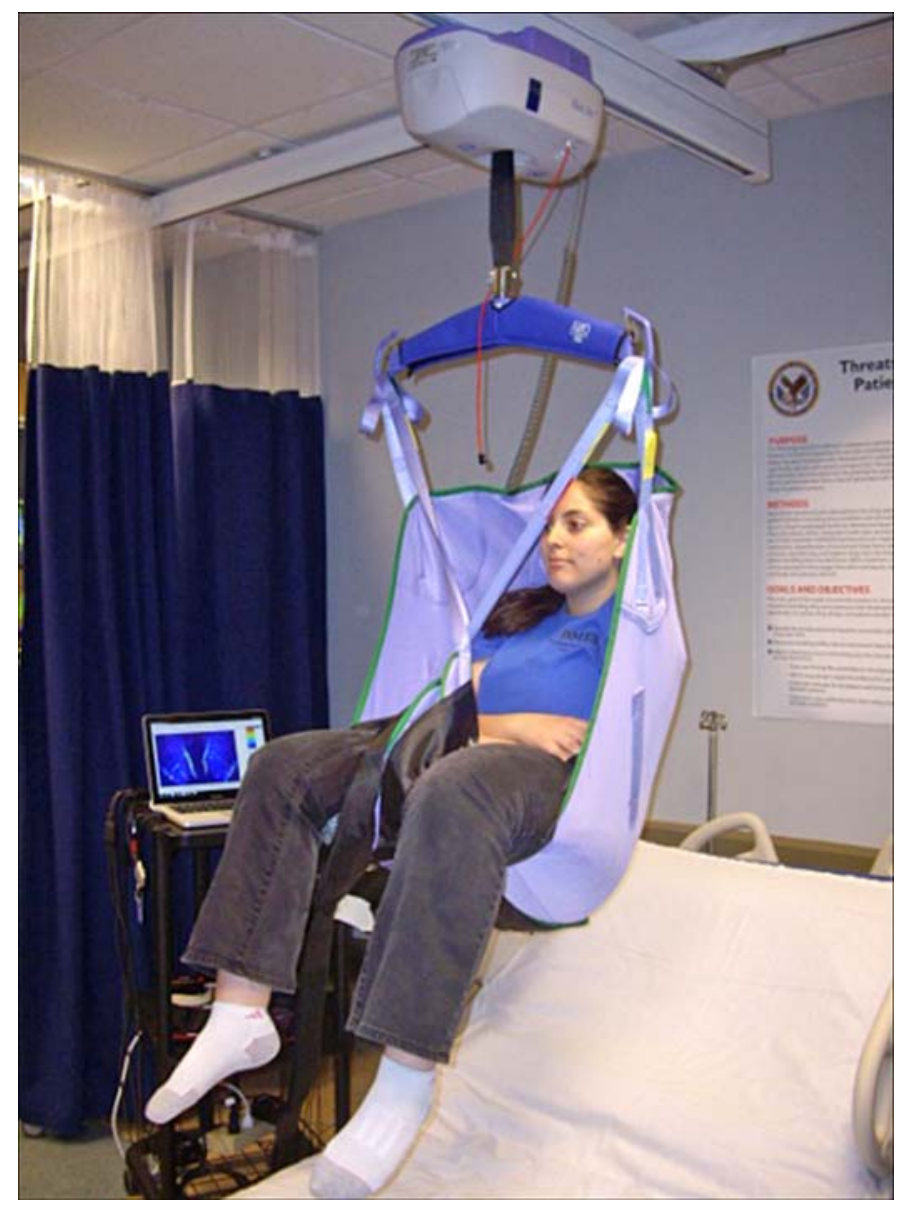

Figure 1.

Example of individual suspended in seated sling with ceiling lift system. (Clothing is not representative of research protocol.)

up about discomfort and would be at near-zero risk for a pressure-related injury as a result of the study. The main goals of this study were to (1) describe and quantify risks associated with safe patient handling sling use and pressure ulceration due to normal forces and (2) identify the atrisk anatomical locations while lying supine on a hospital bed and while suspended during typical patient transfers for various sling designs (e.g., universal, repositioning, hygiene, disposable).

\section{METHODS}

\section{Study Design}

A descriptive, observational study was conducted at a VA clinical research institution. Twenty-three patient 
handling slings (18 seated, 5 supine) were chosen to represent a wide variety of sling styles (e.g., slings with and without head support), materials, and manufacturers. The sample was not exhaustive but selected to provide a representation of what is currently available and used in clinical settings. Slings were selected from three international manufacturers: ArjoHuntleigh (Addison, Illinois), Guldmann Inc (Tampa, Florida), and Liko AB (Luleå, Sweden). Table 1 shows the list of slings evaluated, along with their descriptions.

\section{Participants}

Four nondisabled adult volunteers (3 male, 1 female) comprised this convenience sample. The age of the participants ranged from 21 to $42 \mathrm{yr}$ (mean \pm standard deviation [SD]: $30.0 \pm 8.8 \mathrm{yr}$ ). Their heights ranged from 1.70 to $1.83 \mathrm{~m}(1.75 \pm 0.06 \mathrm{~m})$ and their weights from 59.1 to $87.3 \mathrm{~kg}(76.9 \pm 12.6 \mathrm{~kg})$. Their body mass indexes ranged from 20.4 to $28.4(25.2 \pm 3.4)$.

\section{Instrumentation}

Interface pressure measurements were recorded at $5 \mathrm{~Hz}$ with a high-resolution pressure-mapping system (X3 PRO, XSENSOR Technology Corporation; Calgary,
Canada). This system uses a flexible, thin, $50.8 \times$ $81.0 \mathrm{~cm}(20 \times 32 \mathrm{in}$.) sensor array comprised of 16,000 sensors with a resolution of $0.51 \mathrm{~cm}$ (25 sensors/in. $\left.{ }^{2}\right)$. The sensors use proprietary capacitive technology to measure interface pressures. Individual pressure information from each sensor can be visualized on a computer for real-time visualization and recording. The sensor array was calibrated by the manufacturer to measure pressures from 0 to $200 \mathrm{~mm} \mathrm{Hg}$, with a reported accuracy of \pm 10 percent.

A modern hospital bed with low air loss technology was used for all measurements (VersaCare A.I.R. ${ }^{\circledR}$ Surface, Hill-Rom; Chicago, Illinois). The head of bed (HOB) elevation was measured with the bed's ball-bearing indicator located in the side rail of the bed. A ceiling lift system (Maxi Sky 600, ArjoHuntleigh) was used in a clinical laboratory setting for all participants and slings. The lift system has a safe working load of $272 \mathrm{~kg}$ and a $2.3 \mathrm{~m}$ strap length. A standard 2-point spreader bar was used for all seated slings. The manufacturer-recommended spreader bar (either 8- or 10-point) was used for each of the respective supine slings.

Table 1.

Patient handling slings evaluated.

\begin{tabular}{|c|c|c|c|c|}
\hline Sling & Manufacturer & Type & Material & Feature \\
\hline A. General Purpose Loop Sling with Head Support & ArjoHuntleigh & Seated & Polyester & - \\
\hline C. Mesh Sling with Head Support & ArjoHuntleigh & Seated & Polyester & Hygiene \\
\hline E. Loop Flites & ArjoHuntleigh & Seated & Polyester & Disposable \\
\hline F. Active Micro Plus & Guldmann Inc & Seated & Polyester & - \\
\hline I. Basic High & Guldmann Inc & Seated & Polyester & - \\
\hline J. Basic High & Guldmann Inc & Seated & Polyester Net & Hygiene \\
\hline K. Uni-D & Guldmann Inc & Seated & Nylon & - \\
\hline L. Uni-D High Back & Guldmann Inc & Seated & Nylon & - \\
\hline M. Uni-D High Back Disposable & Guldmann Inc & Seated & Polyester & Disposable \\
\hline R. Solo Highback & Liko AB & Seated & Non-Woven Polypropylene & Disposable \\
\hline S1. Repositioning Sling with Stretcher Frame & ArjoHuntleigh & Supine & Polyester & - \\
\hline S2. Stretcher Sling & ArjoHuntleigh & Supine & Polyester & - \\
\hline S3. Disposable Repositioning with Horizontal Lifting Support & Guldmann Inc & Supine & Polyester & Disposable \\
\hline S4. Octo Lift Sheet with Octo Stretch & Liko AB & Supine & Polyester & - \\
\hline S5. Repositioning Sheet & Liko AB & Supine & Polyester, Cotton & - \\
\hline
\end{tabular}




\section{Protocol}

Participants were dressed in hospital scrubs and positioned supine on the flat hospital bed. The sensor array was placed between the participant and the sling, spanning from the sacrum to the lower thighs to ensure data collection of the predominant weight-bearing tissue areas, i.e., the most common anatomical locations of PU development. The sling and sensor array were positioned on the bed prior to the participant lying on the bed to ensure proper placement beneath the patient, without wrinkles.

Participants underwent a series of positions, transfers, and transports with each sling. Interface pressure measurements were recorded throughout the duration of the protocol. Participants were monitored for $5 \mathrm{~min}$ in each position. This time frame was chosen to allow the subject to get acclimated to the position, to allow enough time for transport if prescribed, and to limit prolonged exposure to potentially high pressures while suspended in the sling. The positioning sequence for the seated slings was as follows: supine on bed $\left(0^{\circ} \mathrm{HOB}\right)$, HOB raised to $30^{\circ}$, sling installation onto the ceiling lift (for an upright seated position), suspension in sling and transport (bed to wheelchair), seated in wheelchair, suspension in sling and transport (wheelchair to bed), and supine on bed (30 HOB) with sling uninstalled from the ceiling lift. The positioning sequence for the supine slings was as follows: supine on bed $\left(0^{\circ} \mathrm{HOB}\right)$, sling installation onto the ceiling lift, suspension in sling and transport, and supine on bed $\left(0^{\circ} \mathrm{HOB}\right)$ with sling uninstalled from the ceiling lift. The entire protocol was completed in approximately $30 \mathrm{~min}$ for each of the seated slings and $20 \mathrm{~min}$ for each of the supine slings. During sling installation and suspension, care was taken to ensure the sensor array was positioned beneath the participant's weight-bearing tissue areas and was not bunched up. After completing each sling sequence, participants were given a questionnaire to describe how they felt with respect to the sling's security, comfort, discomfort, and pain using a 5-item Likert scale. Locations of discomfort and/or pain were marked on a schematic of the body.

\section{Data Analysis}

The interface pressure profiles from the supine on bed $\left(0^{\circ} \mathrm{HOB}\right)$ and suspension in sling positions were used to determine how each of the patient handling slings affected the participants' interface pressures. For clarity, interface pressure data for other positions will be described in a future article. MATLAB (The MathWorks Inc; Natick,
Massachusetts) and Excel (Microsoft Corporation; Redmond, Washington) were used to image, analyze, and compare the interface pressure data. Each pressure profile described the interface pressure (millimeters of mercury) at each of the 16,000 discrete sensors. Interface pressure distributions across the slings were analyzed, and the anatomical locations of high pressures were determined.

For each position of each sling, a representative sample was selected for analysis. Each representative sample consisted of the average of 40 consecutive seconds of interface pressure data (200 profiles) with the least variance. The pressure distributions were analyzed by dividing the calibrated range of pressures into ten divisions $(>0,>20,>40,>60,>80,>100,>120,>140,>160$, and $>180 \mathrm{~mm} \mathrm{Hg}$ ) and summing the number of sensors at each threshold.

The seated and supine slings were ranked overall according to their interface pressure distribution while suspended. The suspended position was chosen because that is the slings' intended purpose (to transfer an individual) and the task that puts individuals at greatest risk. The ranking system criteria chosen for the seated slings minimized the number of sensors exposed to high interface pressures (i.e., average of $>40,>60$, and $>80 \mathrm{~mm} \mathrm{Hg}$; $>100 \mathrm{~mm} \mathrm{Hg}$; and $>180 \mathrm{~mm} \mathrm{Hg}$ ) while also maximizing the number of sensors consisting of lower, or supportive, interface pressures (all sensors $\leq 80 \mathrm{~mm} \mathrm{Hg}$ ). The ranking system criteria chosen for the supine slings, similar to the seated slings but with different thresholds, also minimized the number of sensors exposed to high interface pressures (i.e., average of $>20,>40$, and $>60 \mathrm{~mm} \mathrm{Hg}>>60 \mathrm{~mm} \mathrm{Hg}$; and $>80 \mathrm{~mm} \mathrm{Hg}$ ) while maximizing the number of sensors consisting of lower, or supportive, interface pressures (all sensors $\leq 40 \mathrm{~mm} \mathrm{Hg}$ ). The slings were ranked based on performance for each participant, and the average score for each criterion was evaluated for each sling. Combining all criteria, which were equally weighted, resulted in the overall rank for each type of sling.

Mean response scores were used to describe the questionnaire data.

\section{RESULTS}

\section{Interface Pressure Profiles}

A total of 606,747 interface pressure profiles were recorded from over $33 \mathrm{~h}$ of data collection; each participant was monitored for an average of $8.4 \pm 0.3 \mathrm{~h}$. 


\section{Interface Pressures and Anatomical Areas of Risk}

\section{Seated Slings}

As expected, seated sling interface pressures (Table 2) were greater while participants were suspended in the sling than while they were lying on the sling in bed. Interface pressure magnitudes exceeded $200 \mathrm{~mm} \mathrm{Hg}$ for all participants while suspended for all slings. Slingpatient interface pressures were greatest along the sling seams (edges), regardless of position or type of sling. The anatomical areas exposed to these high pressures were located at the posterior upper and lower thighs toward the groin and knees, respectively. Figure 2 shows examples of interface pressure profiles of seated slings.

Table 2.

Mean interface pressure data for seated slings. Data represent mean tissue area (centimeters squared) that exceeds interface pressure thresholds (millimeters of mercury) for indicated position. Slings are ranked for suspended position from best-performing (lower number) to least-performing (higher number).

\begin{tabular}{|c|c|c|c|c|c|c|c|c|c|c|c|}
\hline \multirow{2}{*}{ Sling } & \multicolumn{10}{|c|}{ Mean Tissue Area Across Interface Pressure Thresholds } & \multirow{2}{*}{ Rank } \\
\hline & $>0$ & $>\mathbf{2 0}$ & $>40$ & $>60$ & $>80$ & $>100$ & $>120$ & $>140$ & $>160$ & $>180$ & \\
\hline \multicolumn{12}{|c|}{${\left.\text { Seated Slings (Supine } 0^{\circ} \mathrm{HOB}\right)}$} \\
\hline A & $1,216.2$ & 696.0 & 59.5 & 9.8 & 3.4 & 1.4 & 0.8 & 0.5 & 0.3 & 0.1 & - \\
\hline $\mathrm{C}$ & $1,096.6$ & 607.8 & 45.9 & 7.6 & 2.2 & 0.9 & 0.5 & 0.3 & 0.1 & 0.1 & - \\
\hline $\mathrm{D}$ & $1,322.4$ & 747.2 & 47.2 & 6.5 & 2.0 & 0.6 & 0.2 & 0.1 & 0.1 & 0.0 & - \\
\hline $\mathrm{E}$ & $1,176.8$ & 703.8 & 53.6 & 6.7 & 1.7 & 0.5 & 0.3 & 0.2 & 0.1 & 0.1 & - \\
\hline G & $1,168.5$ & 703.0 & 40.3 & 3.4 & 0.7 & 0.6 & 0.5 & 0.2 & 0.1 & 0.0 & - \\
\hline $\mathrm{H}$ & $1,282.4$ & 740.4 & 32.7 & 4.4 & 2.1 & 1.1 & 0.7 & 0.5 & 0.3 & 0.1 & - \\
\hline I & $1,162.8$ & 717.0 & 72.3 & 7.9 & 2.2 & 0.7 & 0.5 & 0.4 & 0.2 & 0.2 & - \\
\hline $\mathrm{J}$ & $1,209.1$ & 706.1 & 55.6 & 6.7 & 2.3 & 1.4 & 0.8 & 0.2 & 0.1 & 0.1 & - \\
\hline K & $1,210.3$ & 683.7 & 33.0 & 3.9 & 1.0 & 0.3 & 0.1 & 0.0 & 0.0 & 0.0 & - \\
\hline $\mathrm{L}$ & $1,144.7$ & 655.9 & 29.3 & 3.4 & 0.3 & 0.1 & 0.0 & 0.0 & 0.0 & 0.0 & - \\
\hline $\mathrm{Q}$ & $1,022.3$ & 581.5 & 41.8 & 4.0 & 1.2 & 0.6 & 0.1 & 0.1 & 0.1 & 0.1 & - \\
\hline $\mathrm{R}$ & 998.0 & 547.0 & 38.9 & 9.4 & 3.2 & 1.4 & 0.7 & 0.4 & 0.1 & 0.0 & - \\
\hline Mean \pm SD & $1,157.5 \pm 88.7$ & $668.8 \pm 66.9$ & $43.2 \pm 11.9$ & $5.9 \pm 3.0$ & $1.9 \pm 1.3$ & $0.8 \pm 0.7$ & $0.5 \pm 0.5$ & $0.3 \pm 0.3$ & $0.2 \pm 0.3$ & $0.1 \pm 0.2$ & - \\
\hline \multicolumn{12}{|c|}{ Seated Slings (Suspended) } \\
\hline A & $2,130.9$ & $1,462.2$ & 455.5 & 211.2 & 120.5 & 84.1 & 63.5 & 48.2 & 38.2 & 31.4 & 1 \\
\hline $\mathrm{B}$ & $1,276.3$ & 994.4 & 488.3 & 279.2 & 186.2 & 143.7 & 115.9 & 96.4 & 82.7 & 71.2 & 10 \\
\hline $\mathrm{C}$ & $1,934.3$ & $1,287.7$ & 456.7 & 261.7 & 176.0 & 132.9 & 101.4 & 78.4 & 61.9 & 49.0 & 5 \\
\hline $\mathrm{D}$ & $2,483.0$ & $1,902.5$ & 743.0 & 307.6 & 127.1 & 60.0 & 34.4 & 19.9 & 10.9 & 6.7 & 3 \\
\hline $\mathrm{E}$ & $2,153.7$ & $1,519.4$ & 516.2 & 262.9 & 145.9 & 100.7 & 72.2 & 53.0 & 39.6 & 29.2 & 2 \\
\hline $\mathrm{F}$ & $1,099.7$ & 906.5 & 488.2 & 317.5 & 196.3 & 130.7 & 95.0 & 68.3 & 49.4 & 35.2 & 6 \\
\hline G & $2,062.7$ & $1,386.8$ & 593.9 & 385.8 & 272.2 & 209.1 & 167.6 & 134.8 & 112.8 & 94.4 & 14 \\
\hline $\mathrm{O}$ & $1,853.4$ & $1,250.7$ & 491.8 & 301.2 & 196.4 & 141.7 & 107.3 & 82.3 & 64.9 & 50.4 & 7 \\
\hline $\mathrm{P}$ & $1,683.3$ & $1,137.8$ & 508.1 & 326.9 & 224.2 & 172.1 & 136.3 & 110.5 & 91.8 & 77.7 & 12 \\
\hline $\mathrm{Q}$ & $1,706.9$ & $1,105.5$ & 455.3 & 305.0 & 227.4 & 184.0 & 152.6 & 125.8 & 104.8 & 86.6 & 12 \\
\hline $\mathrm{R}$ & $2,037.4$ & $1,438.7$ & 575.4 & 344.8 & 225.0 & 159.0 & 119.6 & 92.2 & 73.3 & 59.2 & 7 \\
\hline Mean \pm SD & $1,879.5 \pm 306.8$ & $1,282.9 \pm 221.9$ & $521.6 \pm 73.4$ & $317.2 \pm 45.4$ & $214.4 \pm 50.1$ & $160.8 \pm 48.3$ & $126.1 \pm 44.4$ & $99.7 \pm 39.6$ & $80.4 \pm 35.5$ & $65.4 \pm 31.9$ & - \\
\hline
\end{tabular}


JRRD, Volume 52, Number 3, 2015
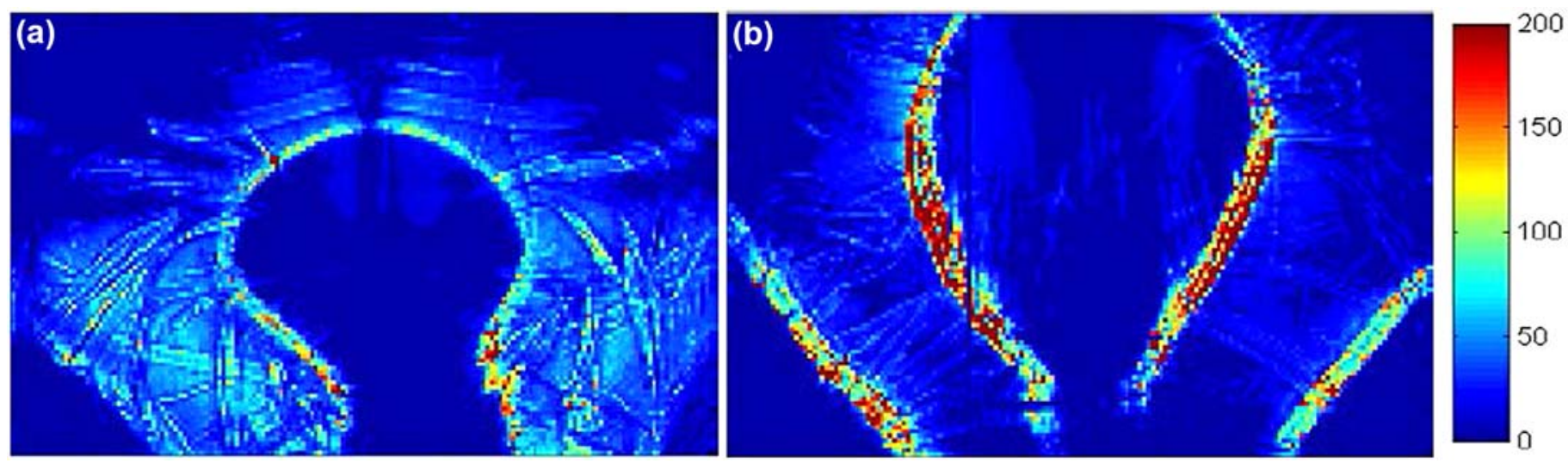

Figure 2.

Interface pressure profile images. Color bar represents interface pressure magnitude in millimeters of mercury. Examples of suspended positions in (a) high-performing and (b) low-performing slings. Note high pressures densely localized along seams and edges.

\section{Supine Slings}

Similarly, supine sling interface pressures (Table 3) were greater while participants were suspended in the sling than while they were lying on the sling in bed. Interface pressures were greatest along the sling seams (edges). The anatomical areas exposed to the highest interface pressures were the tissues of the perisacral area, ischial tuberosities, and greater trochanters. Additionally, the presence of additional sling seams (support straps) on the underside of some of the supine slings greatly increased interface pressures over these load-bearing areas.

\section{Participant Perceptions}

Table 4 details participant perceptions about how they felt while in each of the slings. The anatomical areas of discomfort and pain identified by the participants were primarily located at the sling seams (edges).

\section{Sling Comparisons}

The seated and supine slings were ranked overall according to their performance while suspended (Tables 2-3). Trends in sling performance were not identified based solely on a particular material, manufacturer, or sling style. A few seated slings consistently performed better ( $>1$ SD better than the mean) than others across the four criteria: slings A, D, and E for the three criteria for minimizing tissue area exposed to high interface pressures (average of $>40,>60$, and $>80 \mathrm{~mm} \mathrm{Hg} ;>100 \mathrm{~mm}$ $\mathrm{Hg}$; and $>180 \mathrm{~mm} \mathrm{Hg}$ ) and slings $\mathrm{A}$ and $\mathrm{C}$ for maximizing supportive interface pressures (all pressures $\leq 80 \mathrm{~mm}$
Hg). A few seated slings performed worse ( $>1$ SD worse than the mean) than others across the four criteria: slings $\mathrm{H}, \mathrm{K}$, and $\mathrm{M}$ for pressures $>100 \mathrm{~mm} \mathrm{Hg}$; slings $\mathrm{H}$ and $\mathrm{K}$ for pressures $>180 \mathrm{~mm} \mathrm{Hg}$; slings $\mathrm{B}$ and $\mathrm{F}$ for the average of pressures $>40,>60$, and $>80 \mathrm{~mm} \mathrm{Hg}$; and slings $\mathrm{G}$, $\mathrm{I}$, and $\mathrm{M}$ for maximizing supportive interface pressures (all pressures $\leq 80 \mathrm{~mm} \mathrm{Hg}$ ). For the supine slings, S3 performed better than others across the four criteria: for two of three criteria for minimizing tissue area exposed to high interface pressures (average of $>20,>40$, and $>60 \mathrm{~mm} \mathrm{Hg}$ and $>60 \mathrm{~mm} \mathrm{Hg}$ ) and for maximizing supportive interface pressures (all pressures $\leq 40 \mathrm{~mm} \mathrm{Hg}$ ). The supine sling S5 performed worse than the others for all four criteria.

\section{DISCUSSION}

Patient handling sling use is the standard of care to transfer and transport dependent patients, such as those with SCI, to and from their beds or wheelchairs. These mechanical lifting devices have been shown to prevent healthcare worker injuries, e.g., back injuries, but no literature demonstrates their safety with respect to skin integrity for at-risk patients. This study demonstrates that patient handling slings generate considerable interface pressures on the individuals they suspend during transfers and transports. All seated slings, regardless of sling type or manufacturer, subjected all participants to interface pressures greater than $200 \mathrm{~mm} \mathrm{Hg}$ while suspended. 
Table 3.

Mean interface pressure data for supine slings. Data represent mean tissue area (centimeters squared) that exceeds interface pressure thresholds (millimeters of mercury) for indicated position. Slings are ranked for suspended position from best-performing (lower number) to least-performing (higher number).

\begin{tabular}{|c|c|c|c|c|c|c|c|c|c|c|c|}
\hline \multirow{2}{*}{ Sling } & \multicolumn{10}{|c|}{ Mean Tissue Area Across Interface Pressure Thresholds } & \multirow{2}{*}{ - Rank } \\
\hline & $>\mathbf{0}$ & $>20$ & $>40$ & $>60$ & $>\mathbf{8 0}$ & $>\mathbf{1 0 0}$ & $>120$ & $>140$ & $>160$ & $>\mathbf{1 8 0}$ & \\
\hline S1 & $1,331.4$ & 854.9 & 117.0 & 4.7 & 0.7 & 0.2 & 0.0 & 0.0 & 0.0 & 0.0 & - \\
\hline S3 & $1,378.0$ & 893.0 & 118.8 & 3.8 & 0.2 & 0.0 & 0.0 & 0.0 & 0.0 & 0.0 & - \\
\hline S4 & $1,351.0$ & 897.9 & 127.2 & 10.0 & 1.0 & 0.1 & 0.0 & 0.0 & 0.0 & 0.0 & - \\
\hline S5 & $1,344.0$ & 873.0 & 106.0 & 4.5 & 0.4 & 0.0 & 0.0 & 0.0 & 0.0 & 0.0 & - \\
\hline S1 & $1,559.4$ & $1,024.3$ & 150.1 & 19.0 & 3.6 & 1.3 & 0.3 & 0.1 & 0.1 & 0.1 & 2 \\
\hline S2 & $1,375.5$ & 976.5 & 179.8 & 48.7 & 11.9 & 4.1 & 1.3 & 0.6 & 0.3 & 0.1 & 4 \\
\hline S3 & $1,697.0$ & $1,135.4$ & 83.7 & 5.5 & 0.8 & 0.1 & 0.0 & 0.0 & 0.0 & 0.0 & 1 \\
\hline S4 & $1,423.7$ & $1,075.6$ & 170.2 & 35.8 & 7.9 & 1.8 & 0.7 & 0.2 & 0.1 & 0.1 & 3 \\
\hline S5 & $1,270.3$ & 822.6 & 160.2 & 103.4 & 72.6 & 53.9 & 40.9 & 31.3 & 25.5 & 20.1 & 5 \\
\hline Mean \pm SD & $1,465.2 \pm 148.6$ & $1,006.9 \pm 106.2$ & $148.8 \pm 34.0$ & $42.5 \pm 33.8$ & $19.4 \pm 26.9$ & $12.2 \pm 20.9$ & $8.6 \pm 16.1$ & $6.4 \pm 12.4$ & $5.2 \pm 10.2$ & $4.1 \pm 8.0$ & - \\
\hline
\end{tabular}

Table 4.

Participant perceptions. Data represent mean response to 5-item Likert scale for how participants felt in each sling, where $1=$ least and $5=$ most.

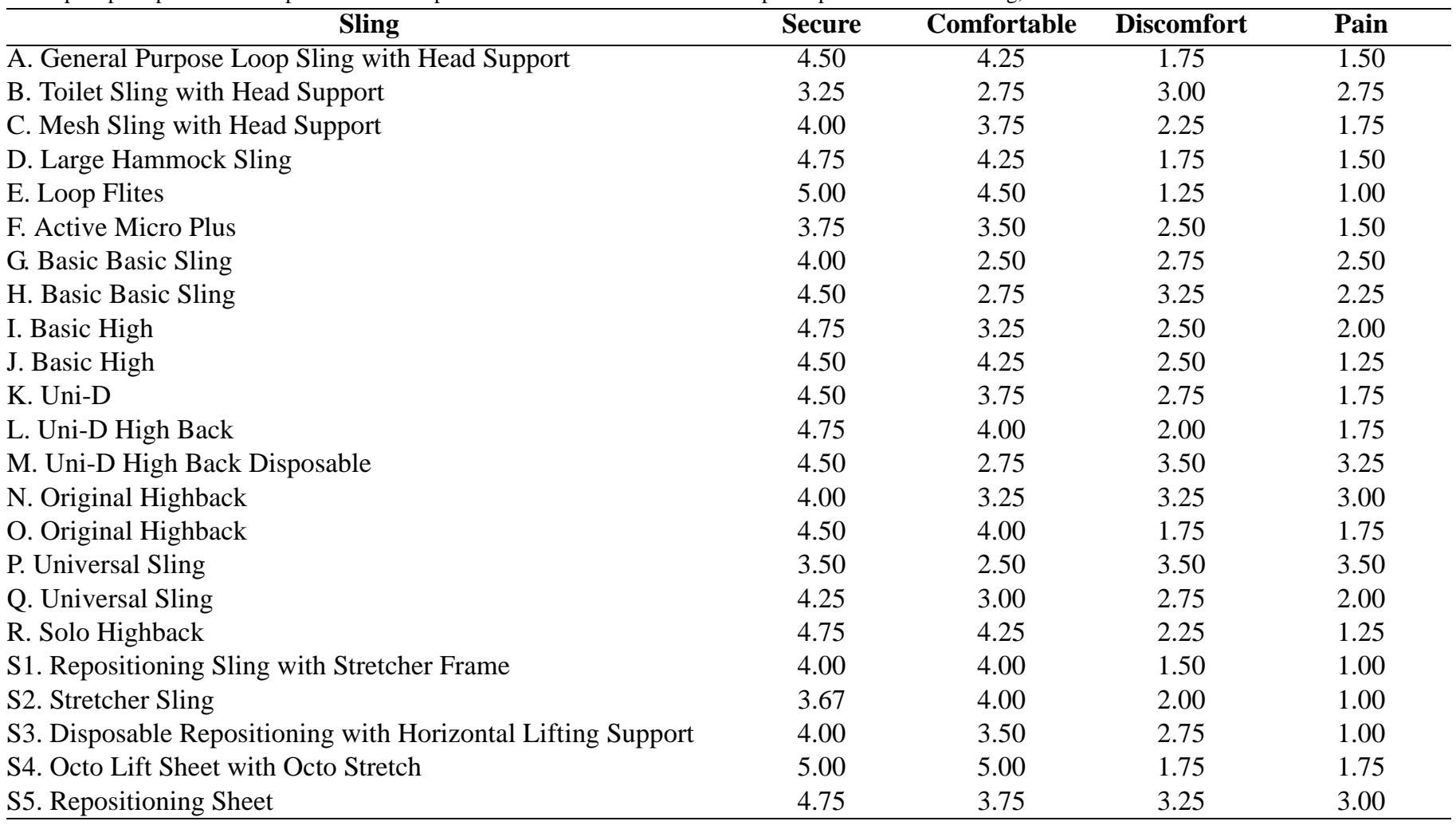

Interface pressures exceeded the calibrated range of the sensor, so peak or maximal interface pressures could not be determined. The supine slings also generated high interface pressures while participants were suspended, although not as high. While there is no widely accepted threshold for PU risk, interface pressures that impede blood flow or cause tissue deformation have the potential to cause pressure ulceration. Exposure to interface pressures greater than $100 \mathrm{~mm} \mathrm{Hg}$, let alone $200 \mathrm{~mm} \mathrm{Hg}$, is a threshold that should be minimized or avoided. 
For the seated slings, the anatomical areas exposed to elevated interface pressures were primarily the posterior upper and lower thighs toward the groin and knees, respectively. Despite the extremely high pressures at the sling seams (edges) while participants were suspended (>200 mm Hg), these pressures were not over the bony prominences where PUs typically develop (e.g., sacrum, coccyx, greater trochanters). While the high pressure areas are not typical areas for PU formation, it would be prudent to limit the duration of these pressures as much as possible. For the supine slings, despite lower magnitude interface pressures, the anatomical areas exposed to the highest interface pressures were over the perisacral area, buttocks, and greater trochanters (and tissue areas across any support straps). Therefore, regardless of the sling type, the amount of time suspended in the sling should be limited.

We are not aware of any prior work examining the interface pressures of individuals suspended in patient handling slings. Therefore, we wanted to gather some participant feedback about security, comfort, discomfort, and pain for the different slings. Generally speaking, the participants' feedback correlated with the sling performance rankings, i.e., those with higher scores for secure and comfortable and lower scores for discomfort and pain corresponded with a better performance ranking. However, there were some exceptions, which indicate that participant feedback cannot be solely relied on for determining a sling's performance.

\section{Recommendations to Reduce Sling Interface Pressures}

To help minimize sling-participant interface pressures, care should be taken that the seams are not beneath the patient when he or she is seated or lying on a sling (not suspended), or if unavoidable, the seams should not be under the sacrum or ischial tuberosities and should be smoothed out to minimize high interface pressures. Additionally, when lifting an individual, one should ensure that the fabric (or seams) does not fold over itself to avoid unnecessarily high interface pressures. If the sling becomes pleated, it essentially doubles or triples the size of the sling seams, thus doubling or tripling the tissue area exposed to elevated interface pressures. Therefore, it is important that the sling is appropriately sized to the individual. Pleating tended to be an issue for slings made of thinner materials and slings with more material. Suspension in a patient handling sling will inevitably result in elevated interface pressures. Therefore, it is recom- mended that the duration of suspension should be monitored and limited. Additionally, providing a slight recline while suspended in the seated position can provide some weight support onto the back, which can help alleviate high interface pressures on the thighs.

\section{Limitations and Future Work}

This study has a few limitations. First, tissue interface pressures do not directly measure internal tissue and capillary pressures; however, elevated interface pressures subject these tissues to increased risk for tissue damage and PU formation. Additionally, pressure is only one of many contributing factors to PU development, which include shear, friction, moisture, and temperature. Second, there were only four subjects, none of whom were obese, so this group did not represent the variety of body habitus seen in clinical practice. Third, minor data collection errors occurred but were resolved. Occasionally, the pressure mapping array would not record a column or two of data, displaying $0 \mathrm{~mm} \mathrm{Hg}$ as the observed interface pressures. If a representative sample had missing data, adjacent column pressure values were interpolated. This correction was needed for less than 2 percent of the total analyzed interface pressure profiles for both seated and supine slings. Fourth, this study only evaluated 23 different safe patient handling slings. This sling sample was a selection of what is currently available and used in clinical settings, but several other manufacturers and styles exist.

Despite these limitations, this research is the first to provide interface pressure data for persons suspended in patient handling slings. Due to the preliminary nature of this work (small number of participants $[n=4]$ ), future research is warranted before extrapolating these results to the clinical setting. Future work is planned to collect data using the best performing slings with at-risk populations, specifically adults with SCI, to determine how their results compare with those of nondisabled adults. Based on prior interface pressure data with individuals at risk for PU development [16], we could expect an increased risk for PU development for individuals with SCI compared with healthy adults. Further research is also warranted to evaluate other patient handling slings of different manufacturers, materials, and sling types, as well as to evaluate other positioning techniques for minimizing interface pressures while individuals are suspended, such as shifting some of the weight-bearing areas from the posterior thighs to the back. 


\section{CONCLUSIONS}

Transferring individuals with patient handling slings exposes them to high interface pressures. Interface pressures are elevated along the sling seams (edges), independent of the sling type or manufacturer. The anatomical areas exposed to high pressures while participants were suspended included the posterior upper and lower thighs toward the groin and knees, respectively, in seated slings and the tissues of the perisacral area, buttocks, and greater trochanters in supine slings. Interface pressures are maximal while individuals are suspended in a sling; therefore, the duration suspended should be limited.

\section{ACKNOWLEDGMENTS}

\section{Author Contributions:}

Study concept and design: M. J. Peterson, M. V. Kerrigan, J. J. Harrow. Acquisition of data: M. J. Peterson, J. A. Kahn, M. V. Kerrigan, J. M. Gutmann.

Analysis of data: M. J. Peterson, J. A. Kahn.

Interpretation of data: M. J. Peterson, J. A. Kahn, M. V. Kerrigan, J. M. Gutmann, J. J. Harrow.

Drafting of manuscript: M. J. Peterson, J. A. Kahn. Critical revision of manuscript for important intellectual content: M. J. Peterson, J. A. Kahn, M. V. Kerrigan, J. M. Gutmann, J. J. Harrow. Financial Disclosures: The authors have declared that no competing interests exist.

Funding/Support: This work was supported by the VA Central Office Occupational Health Strategic Healthcare Group (no. SPTOF00A1).

Additional Contributions: Kathryn Gower is gratefully acknowledged for her assistance with data collection. This work has been presented in part at the Academy of Spinal Cord Injury Professionals Annual Meeting (September 2-4, 2013; Las Vegas, Nevada) and the Safe Patient Handling Conference East Annual Meeting (March 24-28, 2014; Orlando, Florida).

Institutional Review: This study was approved by the James A. Haley Veterans' Hospital VA Research and Development Committee and University of South Florida Institutional Review Board; all participants provided informed consent.

Participant Follow-Up: The authors do not plan to inform participants of the publication of this study.

Disclaimer: The contents of this article are those of the authors alone and do not represent the views of the VA or U.S. Government.

\section{REFERENCES}

1. Spinal cord injury. Facts and figures at a glance. J Spinal Cord Med. 2012;35(6):480-81. [PMID:23318031]

2. Consortium for Spinal Cord Medicine. Pressure ulcer prevention and treatment following spinal cord injury: A clinical practice guideline for health-care professionals. Washington (DC): Paralyzed Veterans of America; 2000.

3. Cuddigan J, Berlowitz DR, Ayello EA. Pressure ulcers in America: Prevalence, incidence, and implications for the future. An executive summary of the National Pressure Ulcer Advisory Panel monograph. Adv Skin Wound Care. 2001;14(4):208-15. [PMID:11902346]

4. Reddy M, Gill SS, Rochon PA. Preventing pressure ulcers: A systematic review. JAMA. 2006;296(8):974-84.

[PMID:16926357]

http://dx.doi.org/10.1001/jama.296.8.974

5. Akins JS, Karg PE, Brienza DM. Interface shear and pressure characteristics of wheelchair seat cushions. J Rehabil Res Dev. 2011;48(3):225-34. [PMID:21480097] http://dx.doi.org/10.1682/JRRD.2009.09.0145

6. Department of Veterans Affairs. MCA reports home page [Internet]. Washington (DC): Department of Veterans Affairs; 2012 [cited 2012 May 14]. Available from:

https://mcareports.va.gov/default.aspx

7. National Pressure Ulcer Advisory Panel. Pressure ulcer category/staging illustrations [Internet]. Washington (DC): National Pressure Ulcer Advisory Panel; [cited 2007 May 7]. Available from:

http://www.npuap.org/resources/educational-and-clinicalresources/pressure-ulcer-categorystaging-illustrations/

8. Reswick JB, Rogers JE. Experience at Rancho Los Amigos Hospital with devices and techniques to prevent pressure sores. In: Kenedi RM, Cowden JM, Scales JT, editors. Bedsore biomechanics. Baltimore (MD): University Park Press; 1976. p. 301-10.

9. Swain I. The measurement of interface pressure. In: Bader DL, Bouten CV, Colin D, Oomens CW, editors. Pressure ulcer research: Current and future perspectives. Berlin (Germany): Springer; 2005. p. 51-71.

10. Stekelenburg A, Gawlitta D, Bader DL, Oomens CW. Deep tissue injury: How deep is our understanding? Arch Phys Med Rehabil. 2008;89(7):1410-13. [PMID:18586145] http://dx.doi.org/10.1016/j.apmr.2008.01.012

11. Amlung SR, Miller WL, Bosley LM. The 1999 National Pressure Ulcer Prevalence Survey: A benchmarking approach. Adv Skin Wound Care. 2001;14(6):297-301. [PMID:11794440] http://dx.doi.org/10.1097/00129334-200111000-00012

12. Nelson A, Matz M, Chen F, Siddharthan K, Lloyd J, Fragala G. Development and evaluation of a multifaceted ergonomics program to prevent injuries associated with patient handling tasks. Int J Nurs Stud. 2006;43(6):717-33.

[PMID:16253260] http://dx.doi.org/10.1016/j.ijnurstu.2005.09.004

13. Nelson A, Fragala G, Menzel N. Myths and facts about back injuries in nursing. Am J Nurs. 2003;103(2):32-40, 41. 
JRRD, Volume 52, Number 3, 2015

\section{[PMID:12582336]}

http://dx.doi.org/10.1097/00000446-200302000-00021

14. Nelson A, Owen B, Lloyd JD, Fragala G, Matz MW, Amato M, Bowers J, Moss-Cureton S, Ramsey G, Lentz K. Safe patient handling and movement. Am J Nurs. 2003; 103(3):32-43, quiz 44. [PMID:12626938]

http://dx.doi.org/10.1097/00000446-200303000-00016

15. National Institute for Occupational Safety and Health. Safe patient handling training for schools of nursing: Curricular materials. Atlanta (GA): Centers for Disease Control and Prevention; 2009.

16. Peterson MJ, Gravenstein N, Schwab WK, van Oostrom JH, Caruso LJ. Patient repositioning and pressure ulcer risk-monitoring interface pressures of at-risk patients. J Rehabil Res Dev. 2013;50(4):477-88. [PMID:23934869] http://dx.doi.org/10.1682/JRRD.2012.03.0040
Submitted for publication June 2, 2014. Accepted in revised form March 3, 2015.

This article and any supplementary material should be cited as follows:

Peterson MJ, Kahn JA, Kerrigan MV, Gutmann JM, Harrow JJ. Pressure ulcer risk of patient handling sling use. J Rehabil Res Dev. 2015;52(3):291-300. http://dx.doi.org/10.1682/JRRD.2014.06.0140

ResearcherID: Matthew J. Peterson, PhD: E-8797-2015; Julie A. Kahn, MS: E-7886-2015; Jeffrey J. Harrow, MD, PhD: E-7878-2015

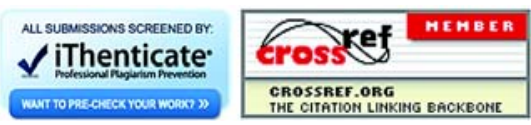

